\title{
DECOMPRESSION OF THE FACIAL NERVE IN CASES OF HEMIFACIAL SPASM
}

\author{
KARSTEN KetTrit *
}

Hemifacial spasm is a well defined disease, consisting of tonic-clonic contractions of all the muscles innervated by a single nerve: the facial nerve. The muscles most commonly afflicted are those around the eye and mouth. Hemifacial spasm may be divided into two groups: primary and post-paralytic.

a) Primary hemifacial spasm, by some authors termed "cryptogenic", "idiopathic" or "autonomous". In reviewing 106 cases Ehni and Woltnan ${ }^{5}$ gave the following characteristics of this group: (1) the spasms are of an intermittent, twitching nature, (2) the eyelids on the ipsilateral side are almost always involved, (3) the spasms are usually unilateral and when bilateral they are not synchronous or equal in extent or severity, (4) the spasms may persist in sleep, (5) the patient does not feel any compulsion to make the movement, (6) the patient is unable to stop the movement by exercise of the will, (7) the patient cannot reproduce the movement voluntarily, (8) psychic upsets of any sort, fatigue and voluntary movements of the face, make the condition worse, (9) children do not have hemifacial spasm and (10) the spasms are limited to muscles innervated by the facial nerve.

It might be added that the contractions generally start in m. orbicularis oculi, and during weeks or months they are spreading to the neighbouring muscles and are intensified in strength and duration. I have, however, seen two cases where violent spasms started suddenly and affected all the facial muscles from the start, on the side afflicted. The spasms may be accompanied by vasomotor and secretory disturbances of the same side of the face. Pain is an uncommon symptom.

b) Postparalytic or "symptomatic" hemifacial spasm. The cause of the symptomatic hemifacial spasm may be intracranial lesions (tumors, aneurism, meningoencephalitis, injuries) causing irritation of the facial nerve or nucleus, resulting in spasm ${ }^{15}$. Among Alajouanine and Thurel's

Relatório apresentado ao XIX Congresso Internacional de Oto-Neuro-Oftalmologia, reunido em São Paulo em 11-17 de junho de 1954, subordinado ao 29 tema oficial: Fisiopatologia do nervo facinl.

* Chief-Surgeon, Frederiksborg County Hospital, Hillerod, Denmark. 
52 cases, 4 were caused by a cerebello-pontine tumor ${ }^{1}$. Most of the postparalytic hemifacial spasms, however, are due to Bell's ischaemic facial palsy.

In a very thorough paper by Williams, Lambert and Woltman ${ }^{20}$ the whole problem is surveyed. They state that "the available evidence suggests that the hemifacial spasm which follows Bell's palsy and the hemifacial spasm called "cryptogenic" are clinically indistinguishable except by history, because muscular weakness and contracture are equally prevalent in both. The evidence also indicates that the etiology of each condition may be the same".

\section{PATHOLOGY}

W'illiams, Lambert and Woltman 20 in their paper state that two hypothesis have been offered as to the cause of the primary as well as the postparalytic hemifacial spasm: (1) the first suggests that hemifacial spasm is a central effect due either to degeneration of celts in the rolandic motor cortex or to degeneration of cells of the facial nucleus in the medulla; (2) the second hypothesis is that hemifacial spasm is a disorder of the lower motor neuron.

In reviewing the experimental work performed by many authors to elucidate this question, Williams, Lambert and Woltman 20 conclude that the hypothesis of the central origin of these spasms is completely untenable. The facts derived trom the clinical and experimental investigations "make it seem highly probable that the lesion causing hemifacial spasm lies somewhere between the facial nucleus and the stylomastoid foramen".

As already outlined, the primary (cryptogenic) and the postparalytic hemiracial spasm are clinically indistinguishable except by history. At present there is a general agreement that Bell's palsy is due to ischaemia near the stylomastoid foramen $2,4.6,12,14,19$. In addition to the alterations found in the facial nerve (haemorrhagic streaks in the sheath and a constriction of the nerve at the stylomastoid foramen with oedema proximal to this point) I have, in 20 of 108 cases (latest check-up, 1954), found bony necrosis in the distal part of the mastoid cells, especially near the stylomastoid foramen, nourished like the nerve by the stylomastoid artery, findings which have been confirmed by other Scandinavian surgeons $7,11,18$ and drawn the conclusion that Bell's palsy is a pathogenetic entity, the primary and central feature being a disorder, a "dysregulation" of the circulation, in most cases affecting only the nutrition of the nerve as the most susceptible tissue, from which an ischaemic paralysis arises, but in others affecting also the nutrition of the facial canal and the mastoid cells, causing bony necrosis.

Williams, Lambert and Woltman 20 on this basis state as follows: "In considering the hypothesis that vasospasm may be the fundamental cause of Bell's palsy, it may be pointed out that vasospasm sufficient to produce necrosis, when it has been observed elsewhere in the body, appears to be associated with tissue in.jury of a sort which maintains a reflex to the affected vessel. It might be considered reasonable to suppose, therefore, that in Bell's palsy and primary or cryptogenic hemifacial spasm, even though vasospasm might play a part in producing the lesion, there might be a still more fundamental tissue lesion tending to set up a reflex, producing the vasospasm. On this basis it occurred to one of us (Woltman) that the fundamental lesion in both hemifacial spasm and Bell's palsy might be a fibrous constriction of the sheath of the facial nerve somewhere in its course through the temporal bone, but probably in close relationship to the stylomastoid foramen." 


\section{OPERATIVE FINDINGS IN HEMIFACIAL SPASMS}

Decompression of the facial nerve was performed by Williams, Lambert and Woltman ${ }^{20}$ on 7 patients suffering from hemifacial spasm and one from blepharospasm, with the following findings: a) in two cases the nerve and the nerve sheath were macroscopically normal; b) in one case a fibrous nodule about $2 \mathrm{~mm}$. across was found attached to the inner sheath at the stylomastoid foramen; c) in 5 cases the nerve sheath near the stylomastoid foramen was tough and resistant to slitting.

My own material consist of 10 cases of hemifacial spasm $(7$ primary and 3 postparalytic, all women) and one of blepharospasm. The idea of decompression in these cases occurred to me (1943) because I had seen 3 cases of Bell's palsy who had spontaneously made a partial recovery marked by contracture, which disappeared in immediate conjunction with the operation. I thought that if the contracture was due to a constant irritation of the facial nerve within the Fallopian canal (Grindstein's theory ${ }^{10}$ ) which eould be relieved by decompression, this might be well worth trying in cases of hemifacial spasm (fig. 1).

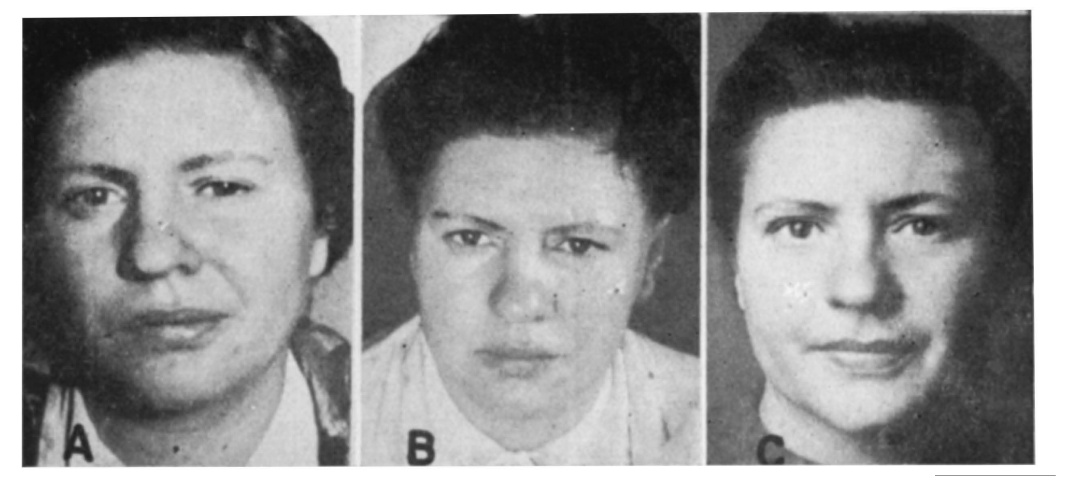

Fig. 1 - A: Bell's palsy of seven month' duration on the left side, with contrature. B: appearance of the patient the day after the operation; the contracture disappeared immediately after decompression without the slightest impairment of the mobility. C: $2 \frac{1}{2}$ years after decompression.

The prompt results which followed my first decompressions made me operate on 11 patients in quick succession. The therapeutic disappointments were to follow later. All the patients have been submitted to a very thorough medical, serological, neurological, otological, ophtalmological and radiological examination expressly to exclude intracranial lesions.

Primary hemifacial spasm ( 7 cases) - All the patients were women, 28-70 years of age, the contractions were severe and had in 6 cases lasted 
between 3 and 9 years. The last patient was operated only one month after onset, because the contractions were violent, and because my results from decompression at that time seemed to be excellent.

The operative findings were as follows: a) in 3 cases the mastoid cells and the nerve looked perfectly normal; I must however admit that not until I read years later (1952) the paper by Williams, Lambert and Woltman ${ }^{20}$, was my attention especially drawn to alterations of the nerve sheath; b) in one case a circumscribed nodule looking like a dilated vessel, 2-3 mm. across, was seen within the nerve sheath just proximal to the stylomastoid foramen; in more than 250 operations on the facial nerve according to the procedure of Ballance and Duel ${ }^{3}$, I have never seen anything similar; c) in one case, operated one month after the onset, the nerve was distinctly oedematous, and bulged through the slit in the nerve sheath, exactly as noted in many cases of Bell's palsy; d) in one case the nerve sheath was yery tough and resistant to slitting; e) in the last case pronounced alterations were encountered.

This patient, a 51-year-old woman, had for 8 years suffered from increasing hemifacial spasms resistant to all medical therapy; apart from this a thorough examination showed nothing abnormal; there was no facial weakness, she had never suffered from ear troubles, and the drums and hearing were perfectly normal. 'The superficial mastoid cells were completely normal but the bone between the posterior osseous wall of the external auditory meatus and the sigmoid sinus, as well as the mastoid tip, was completely necrotic; the wall of the facial canal was very soft and was opened as far as the lateral semicircular canal in a few minutes; the nerve was distinctly oedematous; near the stylomastoid foramen the mastoid cells contained a yellow transudate or exsudate; neither pus, nor granulation tissue were found; microscopy showed granular bony decay and hony necrosis, while on direct examination of the fluid no bacteria were found. A facial weakness followed the operation but disappeared soon, and for 10 months the patient was completely free from hemifacial spasms and synkineses; then they recurred.

One year after the first operation a revision was performed. The bony cavity was normal and in it the facial nerve was lying free; in its proximal half, between the lateral semicircular canal and the stylomastoid foramen, it looked normal; in the distal half, it lay surrounded by connective tissue from which it was freed. This time no facial weakness followed, but the hemifacial spasms were not influenced by the neurolysis. Five years later she was still suffering from severe hemifacial spasm.

Postparalytic hemifacial spasm (3 cases) - All the patients, women 32,40 and 57 years of age, had suffered from Bell's ischaemic palsy (for 8 months, 9 months and 10 years, respectively); in the last two cases a contracture had developed in addition to severe hemifacial spasm.

The operative findings were as follows: a) in two cases (which had lasted 8 months and 10 years, respectively) nothing abnormal was seen in the mastoid cells or the facial nerve; b) in one case of 9 months duration, in which the patient had never suffered from otitis media, and where the objetive examination showed nothing abnormal apart from the 
hemifacial spasm and a contracture, the superficial mastoid cells were large and clear; the cells between the posterior wall of the auditory meatus and the sinus, on the other hand, were smaller and soft, and the facial canal proper appeared so soft that the decompression was completed in a few minutes; in the part deep to the nerve a cavity larger than a hazel-nut was created after the excochleation, and through this cavity the nerve has been running practically uncovered; the cavity passed deeply toward the jugular foramen; the nerve sheath was slit open, and the nerve bulged distinctly.

Blepharospasm (man 19 years old) - Nothing abnormal was found in the mastoid cells or in the nerve.

To sum up Williams, Lambert and Woltman's cases, the nerve and nerve sheath were normal in 2 cases, while in 6 pathological alterations were found near the stylomastoid foramen. Concerning my own cases, it is seen that the mastoid cells in 9 cases were normal, while in 2 cases they were the site of severe alterations as described above. The facial nerve was normal in 6 cases, while in 5 cases alterations of varying nature were encountered at or just above the stylomastoid foramen.

\section{COMMENTS}

The most interesting results of decompression in cases of hemifacial spasm are (a) the pathological alterations, and (b) the disappearance of associated movements of the facial muscles.

Pathological findings - Three clinical entities are known in which all the subjective and objective findings are strictly confined to the region innervated by the facial nerve: (1) Bell's palsy; (2) Melkersonn's syndrome, which consists of a peripheral facial palsy, exactly like Bell's ischaemic, but combined with angioneurotic oedema of the lips and cheek, and sometimes with a lingua plicata; and (3) hemifacial spasm.

In Bell's palsy and Melkersson's palsy the weakness is the essential feature, the postparalytic spasm a rare and secondary phenomenon. Synkineses, more or less pronounced, are, however, a practically constant symptom. In hemifacial spasm contractions are the dominant symptom, weakness being slight or completely lacking. By decompression, however, I have found examples of exactly the same pathological alterations in the mastoid cells near the stylomastoid foramen and in the facial nerve.

1) Bell's palsy: In 20 out of 108 cases I have, as already described, found bony necrosis in the tip of the mastoid cells near the stylomastoid foramen. In 26 cases the wall of the facial canal, normally hard like ivory, was more or less soft, and in the extreme cases completely necrotic. The alterations were exactly like those described above in 2 cases of hemi- 
facial spasm. In 56 cases the nerve was distinctly oedematous, in 3 (long standing palsies) atrophic.

2) Melkersson's syndrome: In 10 cases the mastoid cells were normal, in one a limited area of bony necrosis was found near the stylomastoid foramen. The nerve in 3 cases looked normal, in 8 it was oedematous and bulged distinctly after slitting of the sheath. The last case (described in detail previously) was quite exceptional:

In a patient 30 years of age, suffering from a complete peripheral palsy of 3 months duration, decompression revealed the following alterations: "The superficial cells are large and glossy. In the depth around the antrum and in the cells between the posterior wall of the auditory meatus and the sinus the bone is soft, increasingly so toward the part around the stylomastoid foramen. The entire facial canal is completely necrosed in its distal half, and the remaining part is opened. Neither knife nor scissors was used, but the nerve sheath is seen to be open, and from it a highly oedematous piece of the nerve bulges out, being conically pointed downward and of a grayish pink color. The point of the nerve, however, is of a much darker red color than the remaining part. The piece of the nerve projecting from the opening in the sheath is $7 \mathrm{~mm}$. long. It is resected and examined microscopically. A nerve transplant taken from the ilioinguinal nerve is grafted" (and the mobility reappeared ten months later). Microscopy showed: "oedema of the nerve trunk, fibrinous exsudation, fresh haemorrhage and marked degeneration of axis-cylinders and medullary sheaths, a small vein containing organized remnants of a thrombus, and between nerve and its sheath an accumulation of fluid consisting of oedema and fibrin". There is not the slightest doubt that these alterations are due to disturbance of the blood supply. Neither micro or macroscopic signs of infection were encountered.

3) Hemifacial spasm: As described above, 2 cases were encountered in which pronounced or very pronounced alterations of the mastoid cells were found. In 3 cases the nerve was oedematous. Everything points to ischaemia being the cause of the alteration; in no case were signs of infection found.

Thus Bell's palsy, Melkersson's syndrome and hemifacial spasm have clinical as well as pathological features in common, and are both probably due to vascular disorders near the stylomastoid foramen.

The disappearance of associated movements of the facial muscles This is considered by Williams, Lambert and Woltman ${ }^{20}$ the most interesting result of decompression in hemifacial spasm.

Just like these authors I have noted that the spasms invariably disappeared in immediate conjunction with the operation even if no postoperative weakness of the facial muscles followed $(2$ cases $)$. In cases in which a more or less pronounced facial palsy resulted from decompression, the spasms, when they recurred, appeared months after the postcperative palsy had disappeared. 
As pointed out by Williams, Lambert and Woltman ${ }^{20}$, associated movements have generaliy been attributed to either branching or misdirection of nerve fibers during regeneration. This explanation of associated movements according to Williams, Lambert and Woltman is not in harmony with the disappearance of the synkineses after decompression, which should be explained on the basis of a reversible physiological mechanism, rather than an irreversible anatomical one. "A possible mechanism of hemifacial spasm which appears to fit the observation which have been made assumes the occurrence of spontaneous discharges of interaction or "cross firing" of nerve fibers in the facial canal", illustrated in fig. 2. "There is no conclusive evidence that the mechanism just described is the mechanism of hemifacial spasm. It is only true that, thus far, our observations trave not been inconsistent with this concept. The relief of hemifacial spasm by decompression of the facial nerve suggests that the genesis of the synkinesis and spasm may lie in the facial canal".

\section{SPONTANEOUS ACTIVITY ORIGINATING IN INJURED ZONE}

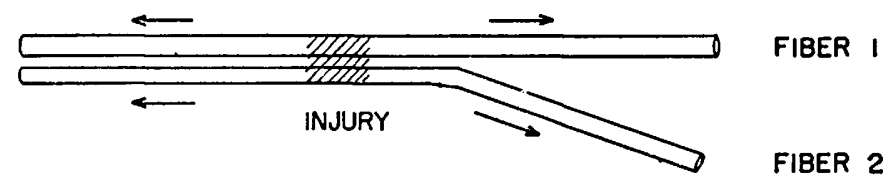

ACTIVATION OF INJURED ZONE BY INCOMING IMPULSE

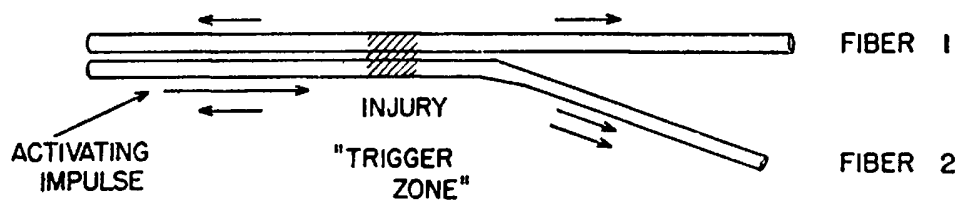

Fig. 2 - A possible mechanism of hemifacial spasm. Fibers 1 and 2 represent axons of the facial nerve innervating the upper and lower parts of the face, respectively. Local injury to the nerve by compression and ischemia in the facial canal is indicated by cross hatching. Upper diagram: spontaneous discharge of impulses (the arrows) from the injured zone produces spasm or contracture. Lower diagram: during interparoxysmal periods, nerve fibers in the injured zone are hyperexcitable. The action current of a "voluntary" impulse in fiber 2 acts as a trigger to the injured zone, causing a discharge of impulse in both fiber 1 and fiber 2, whereas only the impulse in fiber 2 was willed. Synkinesis results from this interaction between nerve fibers. The effects of antidromic impulses in motor fibers and of impulses in sensory fibers have not been considered in this discussion. (Reproduced from Woltman, Williams and Lambert ${ }^{21}$, by courtesy of Dr. Williams). 
In discussing the paper cited, Lathrop ${ }^{\text {t5 }}$ expressed his belief that it is injury to the facial nerve, which has resulted in minor temporary depression of function, which affords the patient the relief from the hernifacial spasm that he obtains.

I am not disinclined to agree with Lathrop ${ }^{15}$. 'The explanation why spasm and synkineses do not return immediately with return of function after the postoperative weakness following decompression, may be, as stated by Williams, Lambert and Woltman ${ }^{20}$, that after all axon dichotony is the explanation of associated movements, and that impaired nerve fibres are more vulnerable to additional injury, so that if only a few axons were involved in this process these might be destroyed by the trauma of surgery or at least be the last to recover.

\section{THERAPY}

Only the treatment of those cases in which medical and neurological therapy had failed shall be discussed here.

Is decompression of the facial nerve the right operation for resistant and severe cases of hemifacial spasm? Williams, Lambert and Woltman ${ }^{20}$ state that the operation of neurolysis for hemifacial spasm has proved somewhat disappointing in that there is a tendency for recurrence of the spasm after a time, although most patients report considerable relief from the procedure.

Williams in a recent personal communication to $O^{\prime}$ Donnell ${ }^{17}$, advised him of the final results in 9 cases, all observed over two years. Five cases had had a short period of relief but the spasm then reappeared as severely as before the operation. This gives three good results and one fair out of nine.

My results are completely in accordance with this statement. All the patients operated on 8-10 years ago have been re-examined 2-10 years after the operation. The number in parenthesis indicates the number of years after the operation when I saw the patient last.

Among 7 cases of primary hemifacial spasm, one patient had recovered completely (10 years); 2 patients were only troubled by faint contractions, and only when they were in a nervous state of mind $(81 / 2-10$ years $) ; 4$ patients were relieved of the spasms for $1 / 2-1$ year, the recurrence took place and the condition is as bad as before operation (3-5-10-10 years). The same applies to the man with blepharospasm (9 years). Among the 3 cases of postparalytic spasm, 2 were only troubled very little by contractions (2-10 years), but in one case the condition was as bad as before (2 years). 


\section{SUMMARY}

Among 11 patients a complete cure was obtained in one case, a fair result in 4 cases, while in 6 cases the effect of the operation has only been temporary and full recurrence has taken place. Even if decompression has thus resulted in a few recoveries and improvements, the results in the majority of cases have been disappointing.

Everything points to hemifacial spasm being due to a disorder of the lower motor neuron. Intracranial lesions in the vicinity of the facial nerve are known to have resulted in irritation and spasm. It may be perfectly true that the majority of cases of hemifacial spasm are due to a lesion, the nature of which may vary, in the Fallopian canal near the stylomastoid foramen, not least the postparalytic following Bell's palsy.

But the disappointing results of decompression seems to indicate that at the time of operation irreparable damage to the nerve has in the majority of cases been already done. Consequently $I$ gave up decompression in cases of hemifacial spasm some years ago.

Good results from injections of alcohol into the nerve have been reported $^{13}$ but I prefer selective sections of the branches to the muscles involved as described by German and Greenwood ${ }^{8}$.

\section{BIBLIOGRAPHY}

1. Alajouanine, 'Th.; Thurel, R. - Les spasmes de la face et leur traitement. Paris Méd., 114:165, 1939. 2. Audibert, V.; Mattei, C.; Paganelli, A. - I a paralysie faciale périphérique dite "a frigore" est fonction d'une atteinte artérielle des vasa nervorum. Presse Méd., 44:1049, 1936. 3. Ballance, C.; Duel, A. B. The operative treatment of facial palsy. Arch. Otolaryng., 15:1-70 (January) 1932. 4. Cawthorne, T. - a) Peripheral facial paralysis: some aspects of its pathology. Laryngoscope, $56: 653,1946 ; b)$ The rôle of surgery in the investigation and treatment of peripheral facial polsy. Lancet, pg. 1219 (June 21) 1952. 5. Ehni, G.; Woltman, H. W. - Hemifacial spasm: review of one hundred and six cases. Arch. Neurol. a. Psychiat, 53:265-211 (March) 1945. 6. Findlay, J. l'. - Facial Paralysis. Angus \& Robertson Ltd., 89 Castlereagh St., Sydney, 1950. 7. Flodgren, E. - Contributions to the surgery of facial palsy. Acta Otolaryng., suppl. 74, pg. 188, 1948. 8. German, W. J. - Surgical treatment of spasmodic facial tic. Surgery, 11:912-914, 1942. 9. Greenwood Jr,, J. - The surgical treatment of hemifacial spasm. J. Neurosurg., 3:506, 1946. 10. Grindstein, A. - Über Contracturen des N. facialis. Zentralblatt $f$. Hals-, Nasen- u. Ohrenh., 8:299, 1926. 11. Hall, A. - Pathology of Bell's palsy. Arch. Otolaryng, 54:475 (November) 1951. 12. Hilger, J. A. - The nature of Bell's palsy. Laryngoscope, 59:228-235 (March) 1949. 13. Jessen, H. - Om hemispasmus facialis $\mathrm{og}$ dens behandling. Ugeskr. f. Laeger, no. 42, pg. 1081, 1940. 14. Kettel, K. a) Bell's palsy. Arch. Otolaryng., 46:427 (October) 1947; b) Melkersson's syndrome. Arch. Otolaryng., 46:341 (September) 1947; c) Om den sakaldte rheumatiske facialisparese set fra et kirurgisk synspunkt. Ugeskr. f. Laeger, no. 10, 
pg. 353, 1953. 15. Lathrop, F. D. - Discussion of paper by Williams, Lambert and Woltman 20. 16. Melkersson, E. - Hygiea, 90:737, 1928. 17. O'Donnell, M. C. - Hemifacial spasm. Ann. Otol., Rhin. a. Laryngol., 62:969 (December) 1953. 18. Skoog, T. - Personal communication to the author. 19. Sullivan, J. A. Recent advances in the surgical treatment of facial paralysis and Bell's palsy. Laryngoscope, 62:449 (May) 1952. 20. Williams, H. L.; Lambert, E. H.; Woltman, H. W. - The problem of synkinesis and contracture in cases of hemifacial spasm and Bell's palsy. Ann. Otol., Rhin. a. Laryng., 61:850, 1952. 21. Woltman, H. W.: Williams, H. L.; Lambert, E. H. - An attempt to relieve hemifacial spasm by neurolysis of the facial nerves. Proc. Staff Meet, Mayo Clin., 26:236240 (June 6) 1951.

$$
\text { Postkonto } 30279 \text { - Hillerod, Denmark. }
$$

